\title{
DEVELOPMENT OF ELECTRICALLY INSULATING COATINGS FOR SERVICE IN A LITHIUM ENVIRONMENT*
}

K. Natesan, M. Uz, and S. Wieder

Energy Technology Division

Argonne National Laboratory

Argonne, IL 60439 USA

\section{May 2000}

\begin{abstract}
The submitted manuscript has been created by the University of Chicago as Operator of Argonne National Laboratory ("Argonne") under Contract No. W-31-109-ENG-38 with the U.S. Department of Energy. The U.S. Government retains for itself, and others acting on its behalf, a paid-up, nonexclusive, irrevocable worldwide license in said article to reproduce, prepare derivative works, distribute copies to the public, and perform publicly and display publicly, by or on behalf of the Government.
\end{abstract}

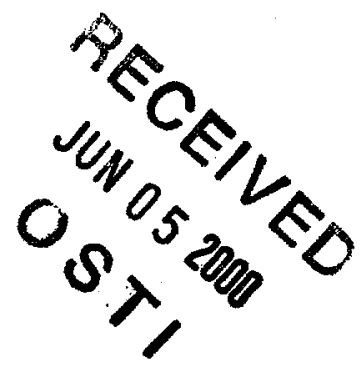

Presented at the 9th International Conference on Fusion Reactor Materials, Oct. 10-15, 1999, Colorado Springs, CO.

*Work supported by Office of Fusion Science, U.S. Department of Energy, under Contract W-31-109-Eng-38. 


\section{DISCLAIMER}

This report was prepared as an account of work sponsored by an agency of the United States Government. Neither the United States Government nor any agency thereof, nor any of their employees, make any warranty, express or implied, or assumes any legal liability or responsibility for the accuracy, completeness, or usefulness of any information, apparatus, product, or process disclosed, or represents that its use would not infringe privately owned rights. Reference herein to any specific commercial product, process, or service by trade name, trademark, manufacturer, or otherwise does not necessarily constitute or imply its endorsement, recommendation, or favoring by the United States Government or any agency thereof. The views and opinions of authors expressed herein do not necessarily state or reflect those of the United States Government or any agency thereof. 


\section{DISCLAIMER}

Portions of this document may be illegible in electronic image products. Images are produced from the best available original document. 
Paper ID code: $\quad 11.7$

Paper Title: $\quad$ DEVELOPMENT OF ELECTRICALLY INSULATING COATINGS FOR SERVICE IN A LITHIUM ENVIRONMENT

Authors: $\quad$ K. Natesan, M. Uz, and S. Wieder

Postal Address: $\quad$ ET-212, Energy Technology Division Argonne National Laboratory

9700 South Cass Avenue Argonne, Il 60439, U.S.A.

Telephone No: (630) 252-5103

Fax No: $\quad$ (630) $252-3604$

e-mail: natesan@anl.gov

Key Words: $\quad$ Coatings and Coated Particles (C06), Chemical Reactions (C04), Compatibility and Corrosion (C08), Electrical Properties (E01), Liquid Metals (L03) 


\title{
DEVELOPMENT OF ELECTRICALLY INSULATING COATINGS FOR SERVICE IN A LITHIUM ENVIRONMENT
}

\author{
K. Natesan, M. Uz, ${ }^{\dagger}$ and S. Wieder ${ }^{\dagger \dagger}$ \\ Energy Technology Division \\ Argonne National Laboratory \\ Argonne, IL 60439, U.S.A.
}

\begin{abstract}
Several experiments were conducted to develop electrically insulating $\mathrm{CaO}$ coatings on a $\mathrm{V}-4 \mathrm{Cr}-4 \mathrm{Ti}$ alloy for application in an Li environment. The coatings were developed by vapor phase transport external to $\mathrm{Li}$, and also in-situ in an $\mathrm{Li}-\mathrm{Ca}$ environment at elevated temperature. In the vapor phase study, several geometrical arrangements were examined to obtain a uniform coating of $\mathrm{Ca}$ on the specimens, which were typically coupons measuring 5 to $10 \times 5 \times 1 \mathrm{~mm}$. After $\mathrm{Ca}$ deposition from the vapor phase, the specimens were oxidized in a high-purity argon environment at $600^{\circ} \mathrm{C}$ to convert the deposited metal into oxide. The specimens exhibited insulating characteristics after this oxidation step. Several promising coated specimens were then exposed to high-purity Li at $500^{\circ} \mathrm{C}$ for $48-68 \mathrm{~h}$ to determine coating integrity. Microstructural characteristics of the coatings were evaluated by scanning electron microscopy and energy-dispersive X-ray analysis. Electrical resistances of the coatings were measured by a two-probe method between room temperature and $700^{\circ} \mathrm{C}$ before and after exposure to $\mathrm{Li}$.
\end{abstract}

\section{Introduction}

Blanket-design studies revealed that electrically insulating duct walls will be required to reduce the magnetohydrodynamic (MHD) pressure drop in liquid-metal-cooled blankets used in high-magnetic-field fusion devices. As a result, development of insulator coatings was recommended as the most appropriate approach for resolving this issue [1]. The major requirements for a viable insulator coating are

- Chemical compatibility in liquid metal.

- Chemical compatibility with structural metal.

- Adequate electrical insulating characteristics.

- Stability under irradiation environment.

- Long-term stability, including self healing, under thermal cycling conditions.

${ }^{\dagger}$ Lafayctte College, Easton, PA.

${ }^{+\dagger}$ Jülich, Germany. 
Based on a review of available information on electrical resistivity values and lithium compatibility, several oxide and nitride candidate materials have been identified for application as insulator coatings. Oxides were generally considered initially as the preferred candidates to meet the specified criteria; however, only a limited number of oxides are stable in Li [2]. Nitrides are generally more stable than the oxides in Li; however, many of the nitrides do not exhibit high electrical resistivity. For example, both VN and TiN are stable in Li but exhibit low resistivity. Similarly, most carbides and silicides do not exhibit adequate resistivity. Therefore, oxides such as $\mathrm{CaO}, \mathrm{Y}_{2} \mathrm{O}_{3}, \mathrm{MgAl}_{2} \mathrm{O}_{4}$, and $\mathrm{Y}_{3} \mathrm{Al}_{2} \mathrm{O}_{12}$, and nitrides such as $\mathrm{AlN}$ and $\mathrm{BN}$, were considered as potential candidates primarily because of their thermodynamic considerations and electrical resistivities. Argonne National Laboratory has been developing $\mathrm{CaO}$ and $\mathrm{AIN}$ coatings on $\mathrm{V}$-alloy substrates for application in V-Li advanced blanket systems. This paper will discuss the procedures used for $\mathrm{CaO}$ coating development, microstructural characteristics of those coatings, and electrical resistivity data for the coatings as a function of temperature. The results will be used to assess the applicability of these coatings in a V-Li self-cooled fusion reactor blanket.

\section{Experimental Procedure}

\subsection{Themal/chemical coating process}

Experiments were conducted to develop Ca-rich coatings by using a thermal/chemical deposition process $[3,4]$. V-alloy specimens were exposed to a pack of fine Ca pellets at 700$800^{\circ} \mathrm{C}$. The specimens were either completely enclosed within the pack or hung above the pack material in a static Ar environment. The temperature dependence of the vapor pressure of $\mathrm{Ca}$ showed that above $700^{\circ} \mathrm{C}$, the Ca vapor pressure is $>0.1$ torr, sufficient to deposit a layer of $\mathrm{Ca}$ on the specimens. Several geometrical arrangements were examined to obtain a uniform coating of $\mathrm{Ca}$ on the specimens, which were typically coupons measuring 5 to $10 \times 5 \times 1 \mathrm{~mm}$. The exposure time in the deposition process ranged from 100 to $200 \mathrm{~h}$. Upon deposition of $\mathrm{Ca}$, the specimens were oxidized in an Ar environment to oxidize the Ca deposit. The oxidized specimens exhibited poor adherence of the oxide to the substrate, and the oxide layer was patchy and fairly thin. A twoprobe method was used to measure the electrical resistance of these specimens by deposition of $\mathrm{Au}$ over $2 \times 2 \mathrm{~mm}$ areas and use of Pt wire for the electrical leads. The specimen assembly was inserted in a furnace, and resistance was measured in an Ar environment between room temperature and $\approx 700^{\circ} \mathrm{C}$.

The coated specimens exhibited insulating characteristics after this oxidation step. X-ray diffraction studies on these specimens showed good correlation between high resistance values at room temperature and a high concentration of $\mathrm{Ca}$ in oxide form. Calcium concentrations in the 
range of 60-80 wt.\% were obtained on several specimens. However, coating thickness in a given specimen or among various specimens was not uniform; in some specimens, coating spallation was noted. The results also showed that $\mathrm{Ca}$ deposition via vapor phase transport is possible but that the coating thickness and the adhesive bonding of the coating to the substrate after a single deposition/oxidation procedure was not adequate to produce the desired insulating characteristics. Additional experiments, with several procedural modifications, were conducted and, finally, a double deposition/oxidation treatment seemed to produce a thicker coating that was more adherent and exhibited adequate insulating characteristics at room temperature.

\subsection{In-situ coating development in-situ in Li-Ca mixture}

In earlier studies, scoping tests were conducted by exposing small coupons of $\mathrm{V}$ alloys at various temperatures to Li containing various concentrations (2-50 at.\%) of calcium [5-7]. A range of conditions (temperature, oxygen pressure, and time) was investigated to determine those that provided better the best coating characteristics. In initial investigations, " $\mathrm{CaO}$ " coatings were obtained by reacting $\mathrm{V}$ alloy coupons in Li-Ca mixtures in small capsules $(<0.1 \mathrm{~L})$ at $400-1000^{\circ} \mathrm{C}$. $\mathrm{CaO}$ coatings $\approx 10 \mu \mathrm{m}$ thick were successfully formed on vanadium alloys. In this case, microcracks were observed at room temperature, but spallation of the coating was not observed. Some of the coated specimens from these experiments, even with nonuniform thicknesses and cracks, were used in resistivity measurements to compare the resistances of the in-situ coatings with those of the coatings developed by the thermal/chemical process.

\subsection{Liquid-metal exposures}

Two static liquid-Li systems were used for studies on compatibility of insulator coatings. The systems were filled with $\approx 15 \mathrm{~L}$ of high-purity $(99.97 \mathrm{wt} . \%) \mathrm{Li}$. Concentrations of trace impurities of $\mathrm{Na}, \mathrm{Ca}, \mathrm{K}, \mathrm{Fe}, \mathrm{Si}$, and $\mathrm{Cl}$ in $\mathrm{Li}$ were $<50 \mathrm{ppm}$, and $\mathrm{N}$ concentration in the $\mathrm{Li}$ was $80 \mathrm{ppm}$. Coupon specimens of $\mathrm{CaO}$-coated samples were exposed in the liquid $\mathrm{Li}$ at $500^{\circ} \mathrm{C}$. Weight change was measured to establish corrosion rates for the coatings as a function of time. After exposure, the specimens were examined by a scanning electron microscope (SEM) equipped with an energydispersive X-ray (EDX) analyzer, and also by X-ray diffraction. The coated specimens were examined to evaluate coating integrity, microstructural changes in coatings, coating/substrate interactions, and electrical insulation characteristics of the coatings.

\section{Results and Discussion}

\subsection{Coatings developed by thermal/chemical process}


Figure 1 shows typical SEM photomicrographs of cross sections of two V-4Cr-4Ti alloy specimens after a double $\mathrm{Ca}$ deposition/oxidation treatment. Coating thicknesses in these specimens were 15 to $30 \mu \mathrm{m}$. EDX analysis of the specimen surfaces showed the coatings to be $\mathrm{CaO}$ and also revealed the virtual absence of any elements from the substrate alloy. Figure 2 shows a typical EDX spectrum of the coating surface and indicates primarily $\mathrm{Ca}$ and $\mathrm{O}$ peaks. Cross sections of several specimens were analyzed as a function of depth for constituent elements of the coating and substrate. Depth profiles for two of the coated specimens are shown in Figs. 3a and $3 \mathrm{~b}$; the profiles indicate coating thicknesses of 16 and $34 \mu \mathrm{m}$, respectively. The coating composition in both specimens was predominantly $\mathrm{CaO}$, and negligible amounts of substrate elements were detected in the coating region. The difference in scale thickness between the two specimens is due to the proximity of different specimens in the $\mathrm{Ca}$ pack. Both specimens, after double $\mathrm{Ca}$ and oxidation treatment, were exposed to $\mathrm{Li}$ of normal purity at $500^{\circ} \mathrm{C}$ for $68 \mathrm{~h}$.

The variation in the product of resistance times area (i.e., $\mathrm{R} \times \mathrm{A}$, which is equivalent to the product of resistivity times coating thickness) as a function of temperature obtained on specimens of $\mathrm{V}-4 \mathrm{Cr}-4 \mathrm{Ti}$ alloy with $\mathrm{Ca}$ deposition/oxidation and with $\mathrm{Ca}$ deposition/oxidation and redeposition of Ca was discussed in Ref. 4. Those results showed that the as-coated specimen (with a double Ca and oxidation treatment) had resistance values of $10^{4}$ to $10^{5} \Omega \cdot \mathrm{cm}^{2}$. In this study, resistance measurements were made on specimens that were double-Ca/oxidation-treated and subsequently exposed to liquid $\mathrm{Li}$ of normal purity at $500^{\circ} \mathrm{C}$ for $68 \mathrm{~h}$. Figure 4 shows the variation in $\mathrm{R} \times \mathrm{A}$ as a function of temperature obtained on a CaO-coated and Li-exposed specimen of $\mathrm{V}-4 \mathrm{Cr}-4 \mathrm{Ti}$ alloy. The figure shows that $\mathrm{R} \times \mathrm{A}$ values are $>10^{7} \Omega \cdot \mathrm{cm}^{2}$ from room temperature to $200^{\circ} \mathrm{C}$; the value gradually decreases to $\approx 5 \times 10^{6} \Omega \cdot \mathrm{cm}^{2}$ as temperature is increased from 200 to $540^{\circ} \mathrm{C}$. The specimen was maintained isothermally at $\approx 540^{\circ} \mathrm{C}$ for $\approx 6 \mathrm{~h}$, after which it was further heated to $\approx 700^{\circ} \mathrm{C}$. Even at $700^{\circ} \mathrm{C}$, the specimen exhibited an $\mathrm{R} \times \mathrm{A}$ value of $10^{4} \Omega \cdot \mathrm{cm}^{2}$, at least two orders of magnitude higher than that required in a fusion device using a Li blanket. Figure 5 shows variation in $\mathrm{R} \times \mathrm{A}$ as a function of exposure time obtained on a $\mathrm{CaO}$-coated and Li-exposed specimen of $\mathrm{V}-4 \mathrm{Cr}-4 \mathrm{Ti}$ alloy. It is evident that the coating had $\mathrm{R} \times \mathrm{A}$ values of $10^{5}$ and $10^{4} \Omega \cdot \mathrm{cm}^{2}$ at 541 and $702^{\circ} \mathrm{C}$, respectively.

\subsection{Coatings developed in-situ}

Specimens of $\mathrm{V}-4 \mathrm{Cr}-4 \mathrm{Ti}$ alloy with a coating of $\mathrm{CaO}$ developed in-situ in an $\mathrm{Li}-\mathrm{Ca}$ environment were examined to characterize the microstructure and coating resistance. Figure 6 is an SEM photomicrograph of the surface of a "CaO"-coated $\mathrm{V}-4 \mathrm{Cr}-4 \mathrm{Ti}$ alloy specimen after exposure to an $\mathrm{Li}$ environment. The surface region consisted of $\mathrm{Li}_{2} \mathrm{O}$ as the outer layer (characterized by a rough, light-toned texture) and a Ca-enriched inner layer (a smooth gray 
texture). Figure 7 shows the variation in $\mathrm{R} x \mathrm{~A}$ as a function of temperature for this specimen. The value for $\mathrm{R} \times \mathrm{A}$ at temperatures up to $\approx 300^{\circ} \mathrm{C}$ is more than the minimum needed, but decreases substantially as temperature rises to $614^{\circ} \mathrm{C}$. Maintaining the specimen at $614^{\circ} \mathrm{C}$ for extended periods seems to improve the resistance of the coating; a further increase in temperature to $713^{\circ} \mathrm{C}$ results in a slight reduction in resistance. In the cooling portion of the cycle, the resistance values are at least two orders of magnitude higher than in the heating portion of the cycle, with a probable inference of coating consolidation/densification and subtle change in chemistry of the coating during the heating portion of the cycle. Figure 8 shows the variation in $\mathrm{R} \times \mathrm{A}$ value as a function of time for the same coated specimen. The results indicate that the resistance values for the coating in the cooling part of the cycle are substantially higher than in the heating portion of the cycle, even though the coating is maintained nominally at the same temperature (e.g., 336/339 and $539 / 538^{\circ} \mathrm{C}$ ) during both the heating and cooling portions of the cycle. Additional experiments are planned in which multiple heating/cooling cycles will be conducted on the same coated sample to evaluate whether the coating characteristics become stabilized and to see whether the coating resistance attains a stable value at each isothermal condition, irrespective of heating or cooling cycle. Further, in-situ measurement of coating resistance (the next logical step to evaluate simultaneously the coating resistance and $\mathrm{Li}$ compatibility) is also planned.

\section{Summary}

We have developed $\mathrm{CaO}$ coatings by a thermal/chemical vapor deposition process and by an in-situ approach in a liquid Li-Ca environment. Results showed that thick adherent coatings can be fabricated by thermal/chemical vapor deposition, especially if a double Ca treatment is applied. Coatings were also developed by the in-situ approach, but the coatings were much thinner than desired. Furthermore, the coating composition was nonuniform, with significant presence of $\mathrm{V}$ in several locations on the coated surface. Extensive microstructural analysis of the coatings developed by the thermal/chemical process showed almost $100 \% \mathrm{CaO}$ over a coating thickness of 20-30 $\mu \mathrm{m}$; electrical resistance (measured by the two-probe method) of the coatings was at least two orders of magnitude higher than the minimum required for blanket application. Electrical resistance of in-situ-developed coatings was adequate at temperatures up to $\approx 350^{\circ} \mathrm{C}$, but decreased substantially at higher temperatures. The results obtained in this study indicate that $\mathrm{CaO}$ is a viable coating for V-Li advanced blankets, but needs significant additional effort, especially from the standpoint of structure/composition relationship to its electrical resistance. Furthermore, in-situ measurement of $\mathrm{Li}$ resistance is required to simultaneously evaluate coating integrity, resistance, and Li compatibility.

\section{Acknowledgments}


This work was supported by the U.S. Department of Energy, Office of Fusion Science, under Contract W-31-109-Eng-38. D. L. Rink assisted with microstructural analysis and resistance measurements of the coated specimens.

\section{References}

1. S. Malang, H. U. Borgstedt, E. H. Farnum, K. Natesan, and I. V. Vitkovski, Development of insulating coatings for liquid metal blankets, Proc. 3rd Intl. Symp. On Fusion Nuclear Technology, Los Angeles, June 27-July 1, 1994, p. 570.

2. C. C. Baker et al., Tokomak Power System Studies FY 1985, Argonne National Laboratory Report ANL/FPP-85-2, 1985.

3. K. Natesan, C. B. Reed, M. Uz, and D. L. Rink, "Development of Electrically Insulating CaO Coatings," Fusion Reactor Materials Progress Report for the Period Ending June 30, 1998, Argonne National Laboratory, DOE/ER-0313/24, p. 82, Sept. 1998.

4. K. Natesan, M. Uz, and S. Wieder, "Development of Electrically Insulating CaO Coatings," Fusion Reactor Materials Progress Report for the Period Ending December 31, 1998, Argonne National Laboratory, DOE/ER-0313/25, p. 69, April 1999.

5. J. H. Park et al., Fusion Engg. and Design, 27, p. 683, 1995.

6. J. H. Park and T. F. Kassner, J. Nucl. Mater. 233-237, p. 476, 1996.

7. R. F. Mattas et al., Fusion Engg. and Design, 40, p. 659, 1998.
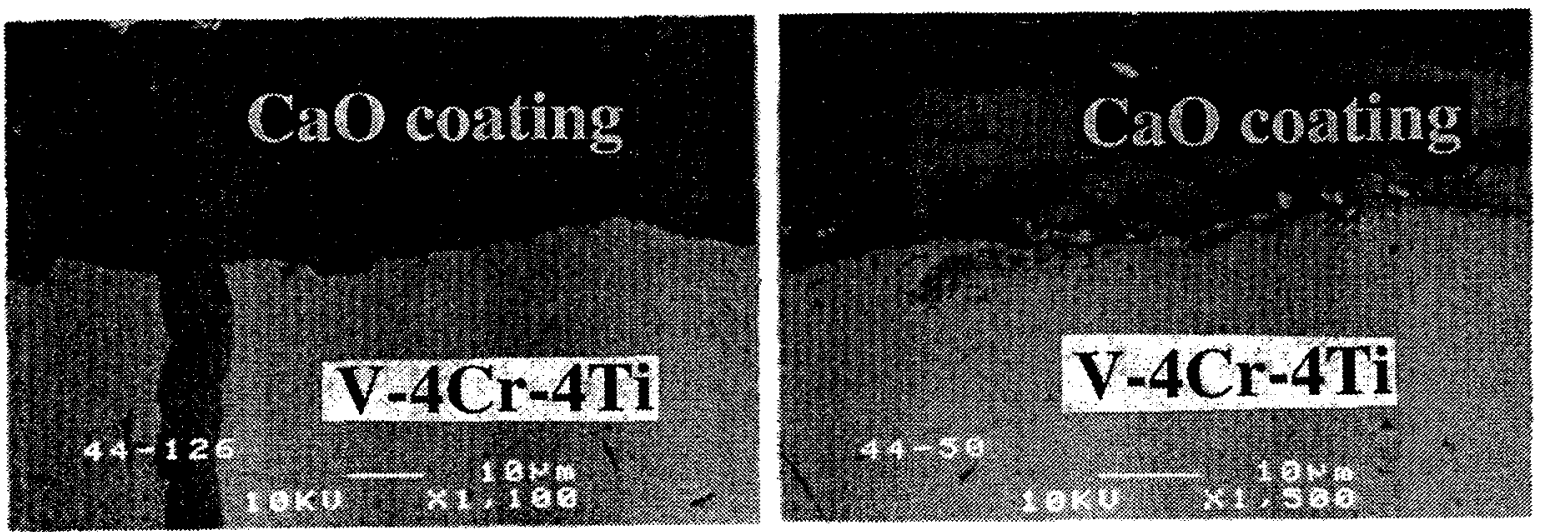

Fig. 1. SEM photomicrographs of cross sections of two $\mathrm{V}-4 \mathrm{Cr}-4 \mathrm{Ti}$ alloy specimens after double $\mathrm{Ca}$ deposition/oxidation treatment. 


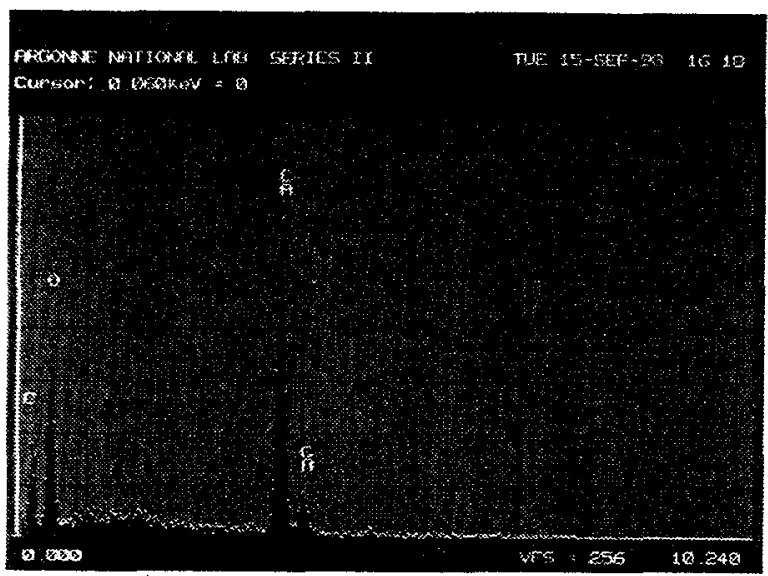

Fig. 2. EDX spectrum of surface of $\mathrm{V}-4 \mathrm{Cr}-4 \mathrm{Ti}$ alloy specimen after double $\mathrm{Ca}$ deposition/oxidation treatment.
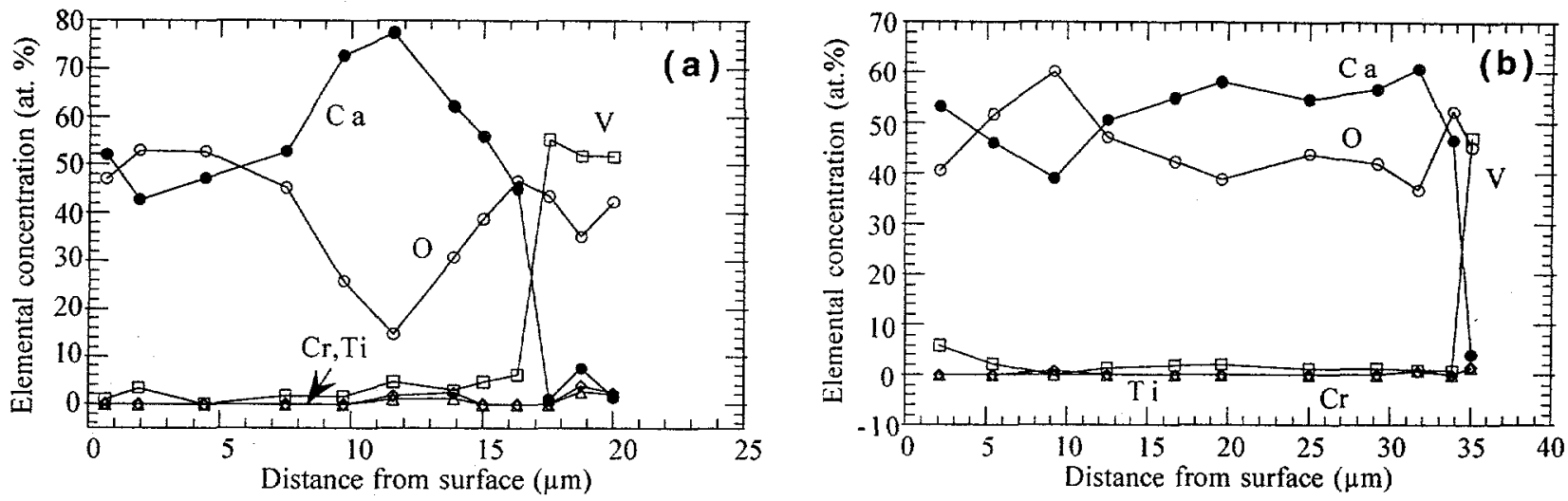

Fig. 3. Elemental concentrations as a function of coating thickness for $\mathrm{V}-4 \mathrm{Cr}-4 \mathrm{Ti}$ alloy specimens after double Ca deposition/oxidation treatment: (a) coating thickness $=16 \mu \mathrm{m}$; (b) coating thickness $=34 \mu \mathrm{m}$.

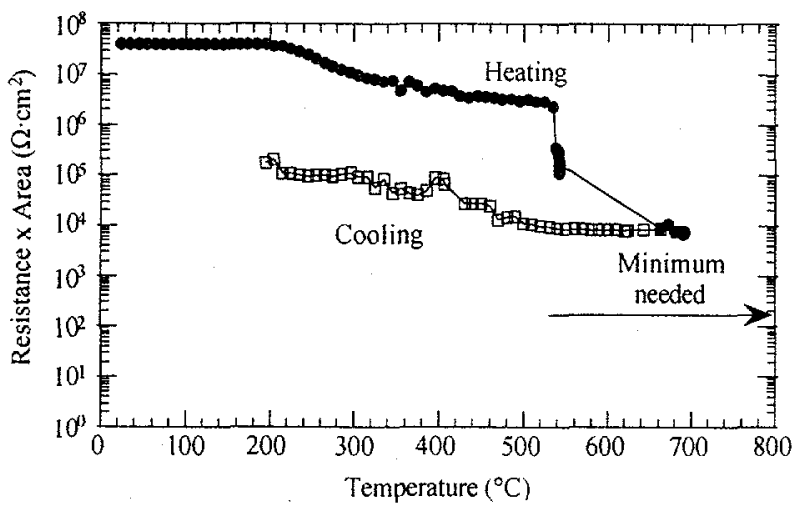

Fig. 4. Product of resistance times area as a function of temperature for $\mathrm{V}-4 \mathrm{Cr}-4 \mathrm{Ti}$ alloy with double $\mathrm{Ca}$ deposition/oxidation after 68 -h exposure in Li environment at $500^{\circ} \mathrm{C}$.

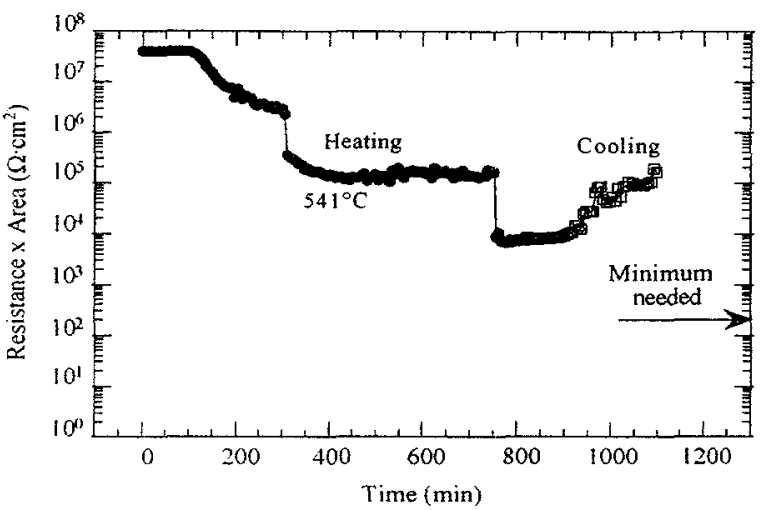

Fig. 5. Product of resistance times area as a function of time for $\mathrm{V}-4 \mathrm{Cr}-4 \mathrm{Ti}$ alloy with double $\mathrm{Ca}$ deposition/oxidation after 68-h exposure in $\mathrm{Li}$ environment at $500^{\circ} \mathrm{C}$. 


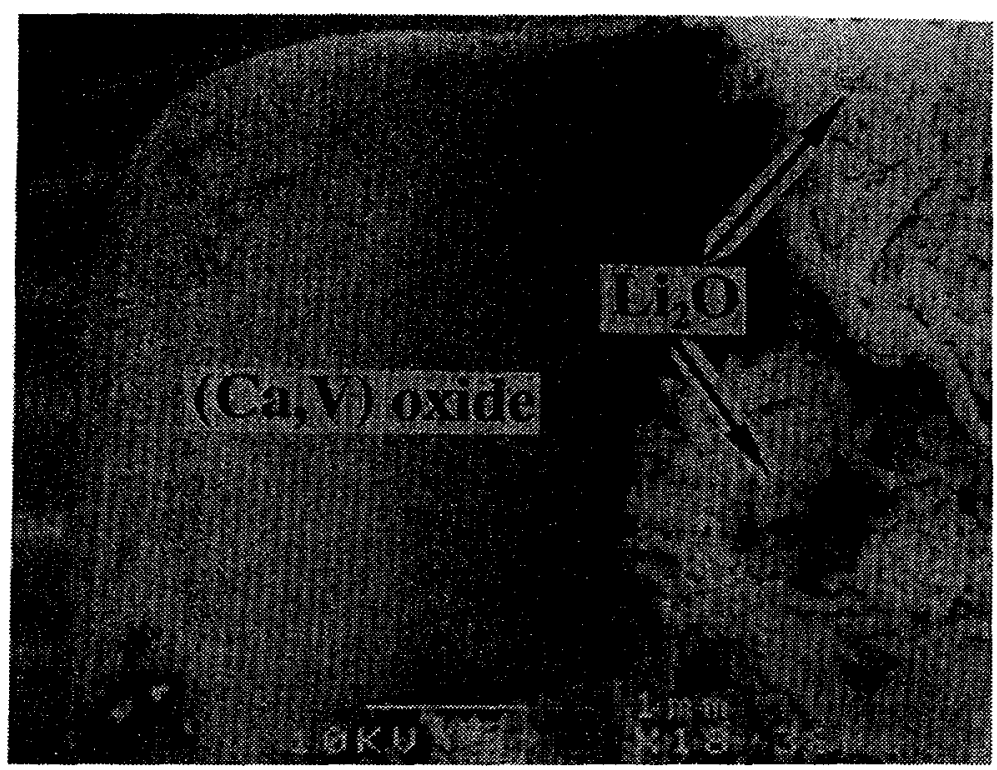

Fig. 6. SEM photomicrograph of surface of $\mathrm{V}-4 \mathrm{Cr}-4 \mathrm{Ti}$ alloy specimen with "CaO" coating developed in-situ in $\mathrm{Li}-\mathrm{Ca}$ mixture.

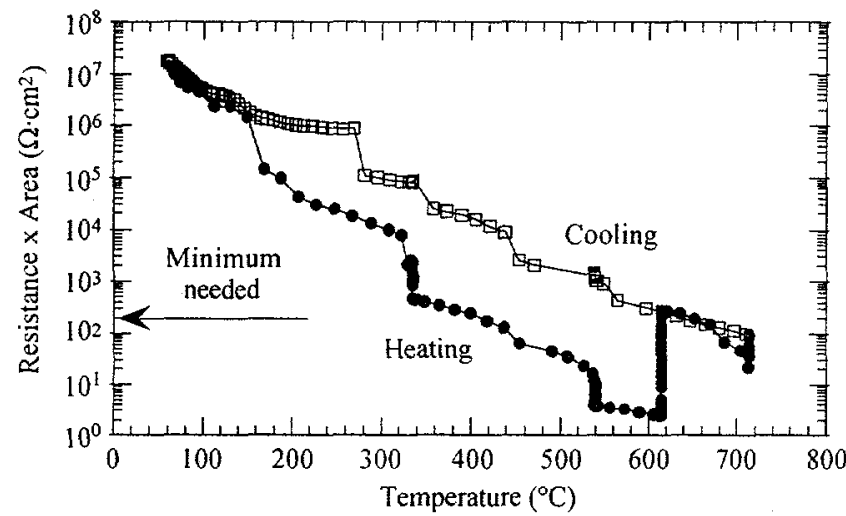

Fig. 7. Product of resistance times area as a function of temperature for $\mathrm{V}-4 \mathrm{Cr}-4 \mathrm{Ti}$ alloy with " $\mathrm{CaO}$ " coating developed in-situ in $\mathrm{Li}-\mathrm{Ca}$ environment

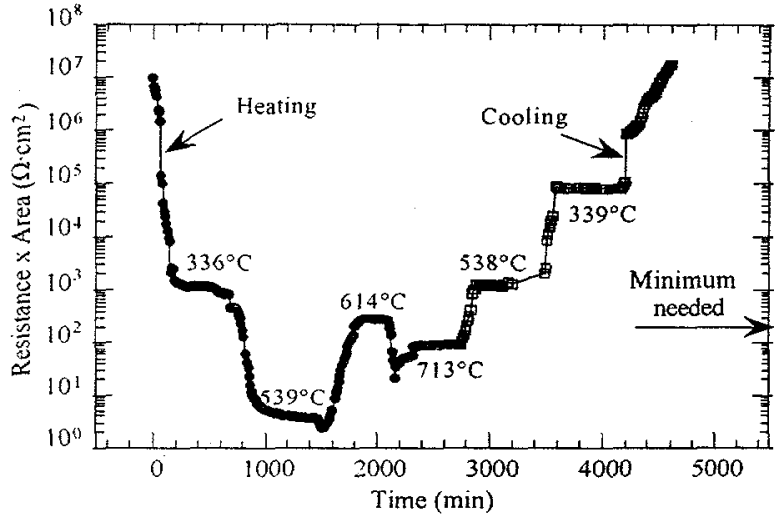

Fig. 8. Product of resistance times area as a function of time for $\mathrm{V}-4 \mathrm{Cr}-4 \mathrm{Ti}$ alloy with "CaO" coating developed in-situ in Li-Ca environment 